\title{
Review
}

\section{Peroxynitrite and inflammatory bowel disease}

\section{Introduction}

Idiopathic inflammatory bowel diseases (IBD), including ulcerative colitis and Crohn's disease, are chronic inflammatory disorders of the gastrointestinal tract which lead an unpredictable clinical course undergoing a succession of exacerbations and remissions of variable intensity. The highest incidence rates for IBD are found in developed countries of the northern hemisphere (UK, Scandinavia, Canada, USA) with the average annual incidence ranging from six to 13 new cases per year per 100000 of the general population. ${ }^{1}$ For the patient, the consequences of IBD include rectal bleeding, diarrhoea, weight loss, and a reduced quality of life and may even result in death (mortality rate for UK, USA, Canada, Scandinavia $\sim 3.9$ per $10^{6}$ per year (combined statistics from 1950 to $1994^{2}$ )).

Investigators working on the aetiology of IBD have proposed many factors which are thought to be involved in the initiation or exacerbation, or both, of the inflammatory process. Some of these factors include increased epithelial permeability, inappropriate neutrophil infiltration into the intestine, activation of mast cells, and increased concentrations of pro-inflammatory mediators (cytokines, leukotrienes, reactive oxygen metabolites (ROMs)). In addition, over the past 10 years, the overproduction of nitric oxide (NO) has received considerable attention as an important player in the pathogenesis of IBD..$^{3-5} \mathrm{NO}^{\circ}$ is a free radical produced from L-arginine via the enzyme nitric oxide synthase (NOS). Alone, $\mathrm{NO}^{\circ}$ is a weak free radical; however, it can react with superoxide $\left(\mathrm{O}_{2}^{-*}\right)$ to produce peroxynitrite $\left(\mathrm{OONO}^{-}\right)$a highly toxic reactive nitrogen intermediary. In 1990, Beckman and colleagues ${ }^{6}$ showed that peroxynitrite had hydroxyl radical ( $\mathrm{OH})$-like activity at physiological $\mathrm{pH}$ and proposed a pathophysiological role for peroxynitrite. This work has since generated substantial interest in the role of peroxynitrite in IBD as it may provide an explanation for pathological roles proposed for both $\mathrm{O}_{2}^{-\cdot}$ and $\mathrm{NO}^{\circ}$ in clinical studies and experimental models of colitis. The role of peroxynitrite in IBD is the focus of this review; however, we should first briefly review the role fulfilled by its individual precursors.

Role of superoxide in inflammatory bowel disease A pathological role for the $\mathrm{O}_{2}^{--}$radical in IBD is generally accepted. ${ }^{78}$ Reactive oxygen metabolites like $\mathrm{O}_{2}^{-}$and hydrogen peroxide $\left(\mathrm{H}_{2} \mathrm{O}_{2}\right)$ are a byproduct of normal cellular metabolism ${ }^{9}$ produced by many enzyme systems (e.g. xanthine oxidase, NADPH oxidase) in the body. Antioxidant enzymes (superoxide dismutase (SOD), catalase, glutathione peroxidase) and free radical scavengers ( $\alpha$ tocopherol, ascorbate, uric acid) are contained in all tissues. Inappropriate oxidative reactions resulting in inflammation will develop when these antioxidants and scavengers are depleted/overloaded by high levels of ROMs. Like NO; $\mathrm{O}_{2}{ }^{-}$ is a relatively weak free radical and its cytotoxic effect is generally ascribed to its role as a precursor for hypochlorous acid and ${ }^{\circ} \mathrm{OH}$ radical formation. Although the iron catalysed Haber-Weiss reaction has been suggested previously to explain the generation of ${ }^{\circ} \mathrm{OH}$ from $\mathrm{O}_{2}^{-\cdot}$ (see A below) the formation of peroxynitrite is another possible mechanism. Hypochlorous acid (B) is generated from $\mathrm{H}_{2} \mathrm{O}_{2}$ and chloride $\left(\mathrm{Cl}^{-}\right)$via myeloperoxidase (MPO), an enzyme which is mainly found in granulocytes and is present in high amounts in intestinal tissue of patients with IBD.

$$
\begin{gathered}
\text { Hydroxyl radical: } \mathrm{O}_{2}^{-\cdot}+\mathrm{H}_{2} \mathrm{O}_{2} \rightarrow \cdot \mathrm{OH}+\mathrm{OH}^{-}+\mathrm{O}_{2} \\
\stackrel{\mathrm{MPO}}{\text { Hypochlorus acid: } \mathrm{H}_{2} \mathrm{O}_{2}+\mathrm{Cl}^{-}+\mathrm{H}^{+} \rightarrow \mathrm{HOCl}+\mathrm{H}_{2} \mathrm{O}}
\end{gathered}
$$

It is well documented that these radicals are generated in high amounts in clinical biopsy samples ${ }^{11}$ and that neutrophils from patients with IBD are capable of generating increased levels of superoxide relative to controls. ${ }^{12}$ SOD and catalase (scavengers of $\mathrm{O}_{2}^{-{ }^{-}}$and $\mathrm{H}_{2} \mathrm{O}_{2}$ respectively) and glutathione are generally decreased in ulcerative colitis and Crohn's disease ${ }^{13}{ }^{14}$ suggesting depletion by high levels of ROMs. Experimental animal models of IBD have demonstrated similarly high levels of ROMs and a benefit of antioxidant therapy. ${ }^{15-17}$ For example, antioxidant therapy has improved the colonic damage and diarrhoea observed in the trinitrobenzene sulphonic acid (TNBS) model of colitis. ${ }^{18}$

Role of nitric oxide in inflammatory bowel disease A pathological role for $\mathrm{NO}^{\circ}$ in IBD is less clear-cut. As stated previously $\mathrm{NO}^{\circ}$ is produced from $\mathrm{L}$-arginine via NOS. NOS exists in three distinct isoforms: constitutively expressed, vascular endothelium (ecNOS or NOS-3) and neuronal NOS (bNOS or NOS-1), and an inducible isoform that operates independently of calcium (iNOS or NOS-2). ${ }^{19}$ iNOS expression is induced by cytokines and requires protein synthesis and is capable of high output production of $\mathrm{NO}^{\circ}$ at sites of inflammation. A role for $\mathrm{NO}^{\circ}$ in IBD has been suggested by various clinical studies which demonstrated the presence of increased levels of nitrite/ nitrates in plasma and $\mathrm{NO}^{\circ}$ in rectal dialysates, as well as increased NOS activity in biopsy samples from patients with ulcerative colitis and Crohn's disease. ${ }^{3420}$ The latter was shown to be calcium independent suggesting increased iNOS activity. iNOS expression has since been demonstrated in numerous cell types in biopsy specimens from patients with ulcerative colitis or Crohn's disease, including neutrophils, macrophages, epithelial cells, and endothelial cells. $^{51-23}$ Although it is well documented that $\mathrm{NO}^{\circ}$ has homoeostatic regulatory functions in the intestine and has many anti-inflammatory mechanisms of action, ${ }^{24-28}$ studies using inhibitors of NOS in experimental models of colitis would suggest that inhibition of $\mathrm{NO}^{\circ}$ production will attenuate the intestinal inflammation. ${ }^{29-31}$ To explain this dichotomy, the prevailing view has been that the small amount of NO produced under normal or acute inflammatory conditions via constitutive NOS (nNOS or eNOS) may be an important endogenous inhibitor of inflammation; however, high levels of $\mathrm{NO}^{\circ}$ associated with chronic inflammatory conditions such as IBD (via iNOS) may be

Abbreviations used in this review: ASA, aminosalicylic acid; COX, cyclooxygenase; IBD, inflammatory bowel disease; IL, interleukin; MEG, mercaptoethylguanidine; MPO, myeloperoxidase; NO, nitric oxide; NOS, nitric oxide synthase; NT, nitrotyrosine; ROM, reactive oxygen metabolites; SOD, superoxide dismutase; TNBS, trinitrobenzene sulphonic acid. 
detrimental to intestinal integrity. Our understanding of the role of $\mathrm{NO}^{\circ}$ in ulcerative colitis and Crohn's disease is further embroiled by a number of other inhibitor studies which have shown little ${ }^{32}{ }^{33}$ or no ${ }^{34}$ effect, or even an exacerbation in experimentally induced inflammation..$^{35}$ One possible explanation for this is the relative lack of specificity of the inhibitors used in these studies which have effects on both the constitutively expressed and the inducible isoform of NOS. Yet, when the iNOS gene is genetically deleted from mice using recombinant DNA technology, experimentally induced colitis is exacerbated acutely. ${ }^{3637}$ In TNBS induced inflammation, the lack of iNOS induction made little difference to the developing chronic inflammation in one study ${ }^{37}$ and improved the mortality rate and some inflammatory indexes in the surviving mice in another. ${ }^{38}$ Furthermore, a chronic colitis which develops spontaneously in interleukin 10 (IL-10) deficient mice, developed at the same rate and intensity in mice which were doubly deficient in IL-10 and iNOS genes. ${ }^{39}$ In addition to this, in a clinical condition (collagenous colitis) which is never associated with obvious macroscopic ulcerations, even higher levels of $\mathrm{NO}^{\circ}$ than in ulcerative colitis are found. ${ }^{40}$ These studies suggest that $\mathrm{NO}^{\circ}$ concentrations alone cannot dictate pathological inflammation in the intestine and makes the generation of peroxynitrite in vivo an exciting prospect, one which could explain the deleterious potential of both $\mathrm{O}_{2}^{-\bullet}$ and $\mathrm{NO}^{-}$in IBD.

\section{Peroxynitrite}

Peroxynitrite has a half life of 1.9 seconds at $\mathrm{pH} 7.4$ and exists in equilibrium with peroxynitrous acid (equation (1) below). ${ }^{6}$ The reactivity of peroxynitrite comes from two possible intermediary products in the degradation pathway of peroxynitrous acid to nitrate $\left(\mathrm{NO}_{3}^{-}\right):(a)$ peroxynitrous acid may generate an excited isomer, defined as $\mathrm{ONOOH}^{\star}$ in equation (2), which acts as a ${ }^{\circ} \mathrm{OH}$-like oxidising species; or (b) homolysis of peroxynitrous acid produces the ${ }^{\circ} \mathrm{OH}$ and nitrogen dioxide $\left(\mathrm{NO}_{2}{ }^{\circ}\right)$ radicals and these free radicals are the oxidants (equation (3) (see Pryor and Squadrito ${ }^{41}$ for review).

$\mathrm{O}_{2}^{-\cdot}+\mathrm{NO}^{\cdot} \rightarrow \mathrm{ONOO}^{-}+\mathrm{H}^{+} \leftrightharpoons \mathrm{ONOOH}^{-}$

$\mathrm{ONOO}^{-}+\mathrm{H}^{+} \leftrightharpoons \mathrm{ONOOH} \leftrightharpoons \mathrm{ONOOH}^{\star} \rightarrow \mathrm{NO}_{3}^{-}+\mathrm{H}^{+}$

$\mathrm{ONOO}^{-}+\mathrm{H}^{+} \leftrightharpoons \mathrm{ONOOH} \leftrightharpoons\left[\mathrm{HO}^{+}+\mathrm{NO}_{2}\right]^{\cdot} \rightarrow \mathrm{NO}_{3}^{-}+\mathrm{H}^{+}$

Thus, through the generation of these potent oxidising intermediaries, peroxynitrite can oxidise a variety of molecules (sulphhydryls ${ }^{42}$, thiols, ascorbate ${ }^{41}$ ) and trigger cytotoxic processes including lipid peroxidation ${ }^{43}$ and DNA damage. The latter can lead to increased permeability in epithelial cells via activation of poly(ADP)-ribose synthetase. ${ }^{45}$ In addition to oxidation reactions, peroxynitrite can nitrate tyrosine in vitro to produce 3-nitrotyrosine (3-NT). This reaction requires the addition of nitronium $\left(\mathrm{NO}_{2}^{+}\right)$to tyrosine residues, a reaction which cannot be produced by $\mathrm{NO}^{\circ}$ itself. ${ }^{46}{ }^{47}$ As peroxynitrite is difficult to measure in vivo owing to its high reactivity, 3-NT formation is used as the standard method for measuring peroxynitrite formation. Detection of 3-NT is most often achieved by antibody immunostaining of tissues although HPLC or GC based spectrophotometry have also been described.

\section{Evidence for peroxynitrite in inflammatory bowel disease}

The formation of 3-NT using immunohistochemical techniques has been found both in clinical biopsy samples from patients with IBD $^{51148}$ and in experimentally induced animal models. ${ }^{49} 50$

Most experimental animal studies on the role of peroxynitrite in IBD have focused on inhibiting the inducible isoform of NOS in an attempt to attenuate $\mathrm{NO}^{\circ}$ production.
In 1996, Southan and colleagues ${ }^{51}$ described a novel class of NOS inhibitors which had increased selectivity for iNOS over both eNOS and nNOS $\left(\mathrm{EC}_{50} 11.5 \mu \mathrm{M} v 110 \mu \mathrm{M}\right.$, iNOS $v$ ecNOS respectively). These drugs belonged to a series of aminoalkylisothioureas, compounds which are thought to exert their potent inhibitory effects through transguanidine rearrangement to mercaptoalkylguanidines such as mercaptoethylguanidine (MEG). ${ }^{51}$ MEG was shown to be almost 10 -fold more potent than aminoguanidine (another "selective" inhibitor), at inhibiting the inducible isoform of NOS. This group later showed that MEG and related compounds could also act as scavengers of peroxynitrite. ${ }^{52} \mathrm{MEG}$ was shown to inhibit peroxynitrite induced DNA single strand breaks, suppress mitochondrial respiration and prevent nitration of 4-hydroxyphenylacetic acid. Therefore, MEG could potentially reduce peroxynitrite formation, yet maintain the physiological effects of NO derived from cNOS. In fact, using the TNBS induced model of experimentally induced colitis in rats, Zingarelli and colleagues ${ }^{50}$ recently reported that administration of MEG significantly attenuated the clinical signs (diarrhoea and weight loss) of colitis as well as macroscopic and histological damage scores, granulocyte infiltration, iNOS immunoreactivity, and 3-NT formation. Previously, Miller and colleagues ${ }^{49}$ showed that aminoguanidine decreased the formation of $\mathrm{NO}^{\circ}$ and 3-NT formation and reduced inflammatory indexes in TNBS induced ileitis. Although compounds such as MEG may be of added benefit in intestinal inflammation owing to their scavenging properties, it is impossible to compare the effectiveness of the two compounds between studies and a direct comparison has not yet been carried out in the literature.

As with aminoguanidine and other "selective" iNOS inhibitors MEG's actions are not limited to this enzyme system. The effects of aminoalkylisothioureas (MEG-like compounds) as protective agents against radiation induced damage have been known since the late $1950 \mathrm{~s}^{53}{ }^{54}$ and may be explained in part by an oxyradical scavenging effect, ${ }^{54} 55$ an effect which in itself may also reduce peroxynitrite formation. MEG has been shown to be a direct inhibitor of both cyclooxygenase 1 (COX-1) and COX-2 activity and this may contribute to its beneficial effects observed in inflammatory conditions. ${ }^{56} \mathrm{MEG}$ also depletes noradrenaline (norepinephrine) stores ${ }^{57}$ when given for 3-4 days in vivo by a direct effect on dopamine $\beta$-hydroxylase, thereby preventing noradrenaline synthesis. ${ }^{58}$ More recently, MEG has been shown to inhibit ADP induced human platelet aggregation by activating guanylate cyclase. ${ }^{59}$

Although peroxynitrite seems to be closely related to iNOS expression in some studies, in other studies this is not the case. Using immunohistochemistry to localise 3-NT formation in the rat ileum after TNBS administration, Miller et al showed staining primarily in the villi epithelial cells and neurones ${ }^{49}$ in the vicinity of iNOS expression. In Zingarelli's recent study ${ }^{38}$ a reduction in the nitrosative and oxidative stress induced by TNBS administration was noted in mice genetically deficient in iNOS. These studies would suggest that increased $\mathrm{NO}^{\circ}$ from iNOS results in, and is required for, increased formation of peroxynitrite. However, in the same experimental model in the colon, iNOS staining was localised to infiltrating inflammatory cells, ${ }^{37} 50$ whereas $3-N T$ staining was found throughout the inflamed tissue..$^{50}$ In agreement with this are findings by Miampamba and Sharkey who recently reported that the formation of 3-NT in the TNBS induced model of colitis was distinct from that of iNOS. ${ }^{60}$ In clinical studies, 3-NT was detected in epithelial cells ${ }^{51148}$ and in the lamina propria ${ }^{11}{ }^{48}$ in patients with ulcerative colitis, Crohn's disease, and diverticulitis. Although Singer et al 
showed intense iNOS immunoreactivity associated with 3-NT expression in epithelial cells, ${ }^{5}$ Dijkstra et al could not visualise 3-NT formation in the epithelium despite intense iNOS staining. In this latter study 3-NT staining was observed at the surface of inflammatory cells producing ROMs, some distance from the iNOS positive epithelium. These data would suggest that NO from iNOS does not necessarily determine the location of peroxynitrite formation and that $\mathrm{NO}^{\circ}$ from other NOS isoforms, as well as the site of ROMs, will also be important.

Direct administration of peroxynitrite in a bolus injection to the rectal mucosa of rats will induce oedema, mucosal ulceration, and severe histological damage.$^{61}$ It is unlikely, however, that peroxynitrite would occur in a bolus form in vivo. Although many cell types are capable of producing both $\mathrm{O}_{2}^{-*}$ and $\mathrm{NO}^{*}$ the relative flux of production has been proposed as an important factor in peroxynitrite formation. For example, Seo and coworkers ${ }^{62}$ measured iNOS activity and SOD protein concentrations in TNBS induced colitis in rats. They reported a reduction in SOD activity and an increase in iNOS activity at a time of severe inflammation and suggested that this might increase peroxynitrite formation in IBD. However, in 1996, Miles and colleagues ${ }^{63}$ showed that peroxynitrite formation, as indicated by oxidation of dihydrorhodamine, was increased (in the absence of redox active iron) but only if $\mathrm{NO}^{\circ}$ and $\mathrm{O}_{2}^{-\cdot}$ were produced in equal amounts. If either $\mathrm{O}_{2}^{-\cdot}$ or $\mathrm{NO}$ were generated in excess, a decrease in peroxynitrite activity was observed. In the presence of redox active iron, $\mathrm{NO}^{\circ}$ production could enhance or inhibit $\mathrm{O}_{2}^{-{ }^{-*}}$ dependent oxidation depending on the relative fluxes of $\mathrm{NO}^{-}$and $\mathrm{O}_{2}^{--}$. This group suggested that $\mathrm{NO}^{\circ}$ could react with a peroxynitrous acid intermediary and effectively reduce its oxidising capacity. The same group extend this work to suggest that as the relative cellular concentration of superoxide is in the order of 1000 times lower than nitric oxide, ${ }^{64}$ the amount of peroxynitrite produced is limited in a site specific fashion to areas of high superoxide anion generation. ${ }^{65}$ The study by Dijkstra and colleagues ${ }^{61}$ in 1998 showing 3-NT formation at the site of ROM formation and not at a site of high $\mathrm{NO}^{\circ}$ output would support this view.

One situation where it has been suggested that $\mathrm{NO}^{\circ}$ and $\mathrm{O}_{2}^{-\cdot}$ production are ideally suited for peroxynitrite production is when L-arginine levels are depleted, such as in chronic inflammation where iNOS is upregulated and NO is produced in excess. ${ }^{66}{ }^{67} \mathrm{Xia}$ and colleagues ${ }^{66}{ }^{67}$ have reported that both nNOS and iNOS are capable of producing $\mathrm{O}_{2}^{-*}$ induced cytotoxicity in cells depleted of L-arginine. This superoxide production could be blocked by L-arginine supplementation and L-NAME, a NOS inhibitor, but not its inactive enantiomer. They hypothesise that $\mathrm{O}_{2}^{-*}$ concentrations were increased and $\mathrm{NO}^{\circ}$ concentrations lowered while being produced in the same locale (by the same enzyme) providing appropriate amounts to generate peroxynitrite which induced the damage. Indeed peroxynitrite concentrations were increased in L-arginine depleted cells as measured by the formation 3-NT and a NOS inhibitor could inhibit this formation. This would suggest that L-arginine supplementation would be beneficial in intestinal inflammation and may explain in part the benefit observed in neonates with necrotising enterocolitis ${ }^{68}$ given a diet high in L-arginine. However, two recent studies would suggest that experimentally induced colitis is exacerbated by L-arginine supplementation, ${ }^{69} 70$ raising issues about the role of $\mathrm{L}$-arginine.

Recently, the practice of detecting 3-NT formation as a specific indicator of peroxynitrite has been questioned. Firstly, Pfeiffer and Mayer demonstrated that tyrosine was nitrated most efficiently with an $\mathrm{NO}^{\circ}$ donor alone in the absence of $\mathrm{O}_{2}^{-*}$ formation. ${ }^{71}$ When $\mathrm{O}_{2}^{-*}$ was generated with
$\mathrm{NO}^{*}$ at equal rates or higher, little or no tyrosine nitrosation could be detected by HPLC. Their results suggested that nitrogen dioxide $\left(\mathrm{NO}_{2}{ }^{\circ}\right)$ was the nitrating agent and not peroxynitrite. Furthermore, using human polymorphonuclear leucocytes, Eiserich and coworkers ${ }^{72}$ showed that in the presence of hypochlorous acid or MPO, 3-NT could be formed from nitrite $\left(\mathrm{NO}_{2}{ }^{-}\right)$, via the formation of nitryl chloride $\left(\mathrm{NO}_{2} \mathrm{Cl}\right)$ and nitrogen dioxide $\left(\mathrm{NO}_{2}{ }^{\circ}\right)$. As previously stated hypochlorous acid is produced from $\mathrm{H}_{2} \mathrm{O}_{2}$ using $\mathrm{Cl}^{-}$and MPO. Their results indicate that 3-NT formation in vivo can result from an action of several reactive nitrogen species not just peroxynitrite and sheds some doubt on the evidence for peroxynitrite formation per se in IBD.

Finally, if peroxynitrite is formed in vivo, could drugs used clinically for IBD affect its production? Sandoval et al have recently reported that 5-aminosalicylic acid (5-ASA) is a potent scavenger of peroxynitrite and attenuated peroxynitrite induced apoptosis in a human intestinal epithelial cell line. ${ }^{73}$ However, this may not be surprising as 5-ASA has previously been described as a scavenger of the superoxide radical. ${ }^{74}{ }^{75}$ Nevertheless, although the mechanism of action of 5-ASA is multifarious, some of its therapeutic effects may be owing to its ability to scavenge peroxynitrite or prevent its formation.

\section{Conclusion}

In summary, the formation of peroxynitrite in vivo would potentially make this molecule a vital regulatory step in the physiology and pathophysiology of both $\mathrm{NO}^{-}$and $\mathrm{O}_{2}^{--}$; balancing a potent oxidant effect with a detoxification pathway for the superoxide radical. The biological formation, activity and decomposition of peroxynitrite is dependent on the chemical environment (concentration of proteins, thiols, sulphydryls, redox active iron), the ratio of $\mathrm{NO}^{-}$to $\mathrm{O}_{2}^{-*}$ production and the cellular source(s) of $\mathrm{NO}^{-}$ and $\mathrm{O}_{2}^{-}$. The exact role of peroxynitrite in IBD cannot be deciphered at present as it is one of many radicals produced in intestinal inflammation and it is impossible to scavenge one without affecting a myriad of others. The problem we are faced with is not whether free radicals can induce damage in intestinal inflammation but rather distinguishing between them. Peroxynitrite, not unlike most radicals, is elusive because of its rapid reactivity. Therefore its detection is based on indirect evidence of the production of 3-NT formation, the end product of a number of different biochemical reactions involving reactive nitrogen metabolites which occur in vivo. What is clear, however, is that reactive nitrogen metabolites are produced in experimental models of IBD as well as in clinical biopsy samples and these metabolites (peroxynitrite included) have the potential to cause damage in the intestine in a similar manner to ROMs. To date "peroxynitrite scavengers" do much more than simply scavenge reactive nitrogen metabolites and therefore the exact contribution of these metabolites to inflammation in IBD cannot be truly elucidated.

Immunology Research Group,

D M McCAFFERTY

Department of Physiology and Biophysics,

Faculty of Medicine,

University of Calgary,

Health Sciences Centre,

3330 Hospital Dr. N.W.

Calgary, Alberta, Canada T2N 4N1

email:dmmccaff@ucalgary.ca

1 Andres PG, Friedman LS. Epidemiology and natural time course of inflammatory bowel disease. Gastroenterol Clin North Am 1999;28:225-81

2 Delco F, Sonnenberg A. Commonalities in the time trends of Crohn's disease and ulcerative colitis. Am f Gastroenterol 1999;94:2171-6.

Boughton-Smith NK, Evans SM, Hawkey CJ, et al. Nitric oxide synthase activity in ulcerative colitis and Crohn's disease. Lancet 1993;342:338-40. 
4 Roediger WeW, Lawson MJ, Nance SH, et al. Detectable colonic nitrite levels in inflammatory bowel disease-mucosal or bacterial malfunction? Digestion 1986;35:199-204.

5 Singer II, Kawka DW, Scott S, et al. Expression of inducible nitric oxide synthase and nitrotyrosine in colonic epithelium in inflammatory bowel disease. Gastroenterology 1996;111:871-85.

6 Beckman JS, Beckman TW, Chen J, et al. Apparent hydroxyl radical production by peroxynitrite: implications for endothelial injury from nitric oxide and superoxide. Proc Natl Acad Sci USA 1990;87:1620-4.

7 Babbs CF. Oxygen radicals in ulcerative colitis. Free Radic Biol Med 1992;13:169-81.

8 Yamada T, Grisham MB. Role of neutrophil-derived oxidants in the pathogenesis of intestinal inflammation. Klin Wochenschr 1991;69:988-94.

9 Chance B, Sies H, Boveris A. Hydrogen peroxide metabolism in mammalian organs. Physiol Rev 1979;59:527-605.

10 Lih-Brody L, Powell SR, Collier KP, et al. Increased oxidative stress and decreased antioxidant defenses in mucosa of inflammatory bowel disease. Dig Dis Sci 1996;41:2078-86.

11 Dijkstra G, Moshage H, van Dullemen HM, et al. Expression of nitric oxide synthases and formation of nitrotyrosine and reactive oxygen species in inflammatory bowel disease. F Pathol 1998;186:416-21.

12 Shiratora Y, Aoki S, Takada $\mathrm{H}$, et al. Oxygen-derived free radical generating capacity of polymorphonuclear cells in patients with ulcerative colitis. Digestion 1989;44:163.

13 Sido B, Hack V, Hochlehnert A, et al. Impairment of intestinal glutathione synthesis in patients with inflammatory bowel disease. Gut 1998;42:485-92.

14 Buffinton GD, Doe WF. Depleted mucosal antioxidant defences in inflammatory bowel disease. Free Radic Biol Med 1995;19:911-18.

15 Loguercio C, D’Argenio G, Delle Cave M, et al. Direct evidence of oxidative damage in acute and chronic phases of experimental colitis in rats. Dig Dis Sci 1996;41:1204-11.

16 Tannahill CL, Stevenot SA, Campbell-Thompson M, et al. Induction and immunolocalization of manganese superoxide dismutase in acute acetic acid-induced colitis in the rat. Gastroenterology 1995;109:800-11.

17 Millar AD, Rampton DS, Chander CL, et al. Evaluating the antioxidant potential of new treatments for inflammatory bowel disease using a rat model of colitis. Gut 1996;39:407-15.

18 Son M, Ko JI, Kim WB, et al. Taurine can ameliorate inflammatory bowel disease in rats. Adv Exp Med Biol 1998;442:291-8.

19 Nathan C, Xie Q-W. Nitric oxide synthases: Roles, tolls and controls. Cell 1994;78:915-18.

20 Rachmilewitz D, Stamler JS, Bachwich D, et al. Enhanced colonic nitric oxide generation and nitric oxide synthase activity in ulcerative colitis and Crohn's disease. Gut 1995;36:718-23.

21 Kolios G, Rooney N, Murphy CT, et al. Expression of inducible nitric oxide synthase activity in human colon epithelial cells: modulation by $\mathrm{T}$ lymphocyte derived cytokines. Gut 1998;43:56-63.

22 Ikeda I, Kasajima T, Ishiyama S, et al. Distribution of inducible nitric oxide synthase in ulcerative colitis. Am f Gastroenterol 1997;92:1339-41.

23 Iwashita E, Iwai A, Sawazaki J, et al. Activation of microvascular endothelial cells in active ulcerative colitis and detection of inducible nitric oxide synthase. F Clin Gastroenterol 1998;27:S74-9.

24 Kubes P, Wallace JL. Nitric oxide as a mediator of gastrointestinal mucosal injury?- Say it ain't so. Mediators of Inflammation 1995;4:397-405.

25 Kubes P, Suzuki M, Granger DN. Nitric oxide: An endogenous modulator of leukocyte adhesion. Proc Natl Acad Sci USA 1991;88:4651-5.

26 Kubes P, Kurose I, Granger DN. NO donors prevent integrin-induced leukocyte adhesion, but not P-selectin-dependent rolling in postischemic venules. Am f Physiol 1994;267:H931-7.

27 Davenpeck KL, Gauthier TW, Lefer AM. Inhibition of endothelial-derived nitric oxide promotes P-selectin expression and actions in the rat microcirculation. Gastroenterology 1994;107:1050-8.

28 De Caterina R, Libby P, Peng HB, et al. Nitric oxide decreases cytokine-induced endothelial activation. Nitric oxide selectively reduces endothelial expression of adhesion molecules and proinflammatory cytokines. F Clin Invest 1995;96:60-8.

29 Rachmilewitz D, Karmeli F, Okon E, et al. Experimental colitis is ameliorated by inhibition of nitric oxide synthase activity. Gut 1995;37: $247-55$

30 Grisham MB, Specian RD, Zimmerman TE. Effects of nitric oxide synthase inhibition on the pathophysiology observed in a model of chronic granulomatous colitis. F Pharm Exp Ther 1994;271:1114-21.

31 Miller MJS, Sadowska-Krowicka H, Chotinaruemol S, et al. Amelioration of chronic ileitis by nitric oxide synthase inhibition. F Pharm Exp Ther 1993; 264:11-16.

32 Ribbons KA, Clark DA, Currie MG, et al. Inducible nitric oxide synthase and idiopathic colitis in rhesus macaques [abstract]. Gastroenterology 1995; 108:A903.

33 Hogaboam CM, Jacobson K, Collins SM, et al. The selective beneficial effects of nitric oxide inhibition in experimental colitis. Am f Physiol 1995; 268: G673-84

34 Conner EM, Chen Y, Grisham MB. Effect of nitric oxide synthase (NOS) inhibition on dextran sulfate sodium (DSS)-induced colitis in rats and mice [abstract]. Gastroenterology 1995;108:A801.

35 Pfeiffer CJ, Qui BS. Effects of chronic nitric oxide synthase inhibition on TNB-induced colitis in rats. F Pharm Pharmacol 1995;47:827-32.

36 McCafferty D, Mudgett JS, Swain MG, et al. Inducible nitric oxide synthase plays a critical role in resolving intestinal inflammation. Gastroenterology
$1997 ; 112: 1122-7$.

37 McCafferty D, Miampamba M, Sihota E, et al. Role of inducible nitric oxide synthase in trinitrobenzene sulphonic acid-induced colitis in mice. Gut 1999;45:864-73.

38 Zingarelli B, Szabo C, Salzman AL. Reduced oxidative and nitrosative damage in murine experimental colitis in the absence of inducible nitric oxide synthase. Gut 1999;45:199-209.

39 McCafferty D, Muscara M, Wallace JL, et al. Role of inducible nitric oxide synthase (iNOS) in spontaneously developing colitis in mice [abstract]. Gastroenterology 1999;116:A773.

40 Perner A, Hillingso J, Nordgaard I, et al. Nitric oxide in colonic inflammation: Proinflammatory mediator or protective factor [abstract]? Gut 1997;41:A17.

41 Pryor WA, Squadrito GL. The chemistry of peroxyniytrite: a product from the reaction of nitric oxide with suoperoxide. Am F Physiol 1995;268:L722.
42 Radi R, Beckman JS, Bush KM, et al. Peroxynitric oxidation of sulfhydryls. The cytotoxic potential of superoxide and nitric oxide. $\mathcal{F}$ Biol Chem 1991;266:4244-50.

43 Radi R, Beckman JS, Bush KM, et al. Peroxynitrite-induced membrane lipid peroxidation: the cytotoxic potential of superoxide and nitric oxide. Arch Biochem Biophys 1991;288:481-7.

44 Rubbo H, Radi R, Trujillo M, et al. Nitric oxide regulation of superoxide and peroxynitrite-dependent lipid peroxidation. Formation of novel nitrogencontaining oxidized lipid derivatives. F Biol Chem 1994;269:26066-75.

45 Kennedy M, Denenberg AG, Szabó C, et al. Poly(ADP-ribose) synthetase activation mediates increased permeability induced by peroxynitrite in Caco-2BBe cells. Gastroenterology 1998;114:510-18

46 Van der Vliet A, O'Neill CA, Halliwell B, et al. Aromatic hydroxylation and nitration of phenylalanine and tyrosine by peroxynitrite. Evidence for 92 .

47 Ischiropoulos $\mathrm{H}$, Zhu L, Chen M, et al. Peroxynitrite-mediated tyrosine nitration catalyzed by superoxide dismutase. Arch Biochem Biophys 1992;298:431-7.

48 Kimura H, Hokari R, Miura S, et al. Increased expression of an inducible isoform of nitric oxide synthase and the formation of peroxynitrite in colonic mucosa of patients with active ulcerative colitis. Gut 1998;42:180-7.

49 Miller MJS, Thompson JH, Zhang X-J, et al. Role of inducible nitric oxide synthase expression and peroxynitrite formation in guinea pig ileitis. Gastroenterology 1995;109:1475-83.

50 Zingarelli B, Cuzzocrea S, Szabo C, et al. Mercaptoethylguanidine, a combined inhibitor of nitric oxide synthase and peroxynitrite scavenger, reduces trinitrobenzene sulfonic acid-induced colonic damage in rats. $\mathcal{F}$ Pharm Exp Ther 1998;287:1048-55.

51 Southan GJ, Zingarelli B, O'Connor M, et al. Spontaneous rearrangement of aminoalkylisothioureas into mercaptoalkyguanidines, a novel class of nitric oxide synthase inhibitors with selectivity towards the inducible isoform. $\mathrm{Br}$ fPharmacol 1996;117:619-32.

52 Szabo C, Ferrer-Sueta G, Zingarelli B, et al. Mercaptoethylguanidine and guanidine inhibitors of nitric oxide synthase react with peroxynitrite and protect against peroxynitrite-induced oxidative damage. f Biol Chem 1997; 272:9030-6.

53 Doherty DG, Burnett WT. Protective effect of S,baminoethylisothiouronium. Br. $\mathrm{HBr}$ and related compounds against X-radiation death in mice. Proc Soc Exp Biol Med 1955;89:312-14.

54 Shapira R, Doherty DG, Burnett WT. Chemical protection against ionizing radiation. III. Mercaptoalkylguanidines and related isothiouronium compounds with protective activity. Radiat Res 1957;7:22-34.

55 Thiemermann C, Ruetten H, Wu CC, et al. The multiple organ dysfunction syndrome caused by endotoxin in the rat: attenuation of liver dysfunction by inhibitors of nitric oxide synthase. Br f Pharmacol 1995;116:2845-51.

56 Zingarelli B, Southan GJ, Gilad E, et al. The inhibitory effects of mercaptoalkyguanidines on cyclooxygenase activity. $\mathrm{Br} f$ Pharmaco 1997;120:357-66.

57 DiStefano V, Klahn JJ. Depletion of cardiac norephinephrine in the mouse and cat by mercaptoethylguanidine. F Pharmacol Exp Ther 1966;151:23641.

58 Dilberto EJ, DiStephano V. Effects of 2-mercaptoethylguanidine and other compounds on norephinephrine synthesis by adrenal medullary granules. Pharmacol 1973;22:2947-60.

59 Severina IS, Bussygina OG, Belushkina NN, et al. Guanidine thiol-a new activator of soluble guanylate cyclase with anti-hypertensive and antiaggregatory properties. Biochem Mol Biol Int 1995;36:913-25.

60 Miampamba $M$, Sharkey KA. Temporal distribution of neuronal and inducible nitric oxide synthase and nitrotyrosine during colitis in rats. Neurogastroenterol Motil 1999;11:193-206.

61 Rachmilewitz D, Stamler JS, Karmeli F, et al. Peroxynitrite-induced rat colitis-A new model of colonic inflammation. Gastroenterology 1993;105: 1681-8.

62 Seo HG, Takata I, Nakamura M, et al. Induction of nitric oxide synthase and concomitant suppression of superoxide dismutases in experimental colitis in rats. Arch Biochem Biophys 1995;324:41-7.

63 Miles AM, Bohle DS, Glassebrenner PA, et al. Modulation of superoxidedependent oxidation and hydroxylation reactions by nitric oxide. $\mathcal{F}$ Biol Chem 1996;271:40-7.

64 Wink DA, Mitchell JB. The chemical biology of nitric oxide: insights into regulatory, cytotoxic and cytoprotective mechanisms of nitric oxide. Free Radic Biol Med 1998;25:434-56.

65 Grisham MB, Jourd'heuil D, Wink DA. Nitric oxide I. Physiological chemistry of nitric oxide and its metabolities: implications in inflammation. $\mathrm{Am}$ f Physiol 1999;276:G315-21.

66 Xia Y, Dawson VL, Dawson TM, et al. Nitric oxide synthase generates superoxide and nitric oxide in arginine-depleted cells leading to peroxynitrite-mediated cellular injury. Proc Natl Acad Sci USA 1996;93: 6770-4.

67 Xia Y, Zweier JL. Superoxide and peroxynitrite generation from inducible nitric oxide synthase in macrophages. Proc Natl Acad Sci USA 1997;94:6954-8

68 Di Lorenzo M, Bass J, Krantis A. Use of L-arginine in the treatment of experimental necrotizing enterocolitis. F Pediatr Surg 1995;30:235-41.

69 Dobosz M, Mionskowska L, Dobrowolski S, et al. Is nitric oxide and heparin treatment justified in inflammatory bowel disease? An experimental study. 6:657-63.

70 Neilly PJ, Kirk SJ, Gardiner KR, et al. Manipulation of the L-arginine-nitric oxide pathway in experimental colitis. Br F Surg 1995;82:1188-91.

71 Pfeiffer S, Mayer B. Lack of tyrosine nitration by peroxynitrite generated at physiological pH. F Biol Chem 1998;273:27280-5.

72 Eiserich JP, Hristova M, Cross CE, et al. Formation of nitricoxide-derived inflammatory oxidants by myeloperoxidase in neutrophils. Nature 1998; 391:393-7.

73 Sandoval A, Liu X, Mannick EE, et al. Peroxynitrite-induced apoptosis in human intestinal epithelial cells is attenuated by mesalamine. Gastroenterology 1997;113:1480-8.

74 Halliwell B: Sulphasalazine and oxidant scavenging in ulcerative colitis. Lancet 1987;ii:635.

75 Craven PA, Pfanstiel J, Saito R, et al. Actions of sulfasalasine and 5 -aminosalicylic acid as reactive oxygen scavengers in the suppression of bile acid-induced increases in colonic cell loss and proliferative activity. Gastroenterology 1987;92:1998-2008. 